\title{
O NEOLIBERALISMO PERIFÉRICO E A CONSTITUIÇÃO FEDERAL DE 1988 NO CONTEXTO DA ECONOMIA GLOBALISTA
}

http://dx.doi.org/10.21527/2176-6622.2019.51.111-122

Recebido em: 16/3/2018

Aceito em: 18/5/2019

\section{Marisa Rossignoli}

Graduação em Economia pela Unesp. Mestrado em Economia (Economia Política) pela PUC-SP e Doutorado em Educação (política e gestão) pela Universidade Metodista de Piracicaba - Unimep. É docente da área de Economia do Programa de Mestrado e Doutorado em Direito da Universidade de Marília - Unimar. Delegada Municipal do Conselho Regional de Economia - Corecon-SP - para a cidade de Marília-SP. mrossignoli@unimar.br

Vinícius Rocha Pinheiro Machado

Mestrando em Direito na Universidade de Marília - Unimar. Especialização em Direito Notarial e Registral. Oficial de Registro de Imóveis, Título, Documento, Civil e Pessoas Jurídicas em Assis-SP. vinicius.rpm@hotmail.com

\section{RESUMO}

O artigo aborda o neoliberalismo tendo por objetivo compreendê-lo no contexto da economia globalista sob a perspectiva da Constituição Federal de 1988. Parte de uma análise acerca das primeiras teorias econômicas que lançaram base aos modelos de Estado de Bem-Estar Social e Estado Neoliberal, neste ponto compreendendo as intersecções entre Direito e Economia com foco na autonomização ou não das ordens jurídica e econômica. Em seguida, analisa as características dos modelos econômicos do Welfare State e do Neoliberalismo. Por fim, estuda o modelo jurídico-econômico da Constituição Federal de 1988, concluindo que, embora o texto constitucional tenha ofertado a proposta de um welfare socialdemocrata, na prática se efetivou uma agenda neoliberal, como decorrência de pressões internacionais que tomaram força em tempos globalizados, em meio a processos de consolidação de um welfare conservador e corporativista, que apenas serve para justificar o agigantamento estatal e não para reduzir desigualdades. A metodologia adotada é a revisão bibliográfica e documental com uso do método dedutivo. Os pensamentos de Adam Smith e Keynes conduzem a linha de argumentação do artigo.

Palavras-chave: Estado de Bem-Estar Social. Globalização. Intervenção do Estado na Economia. Neoliberalismo.

\section{THE PERIPHERAL NEOLIBERALISM AND THE FEDERAL CONSTITUTION OF 1988 IN THE CONTEXT OF GLOBALIST ECONOMY}

\section{ABSTRACT}

The article approaches the neoliberalism aiming to understand it in the context of the globalist economy from the perspective of the Federal Constitution of 1988. It departs from an analysis of the first economic theories that have laid the basis to the models of welfare state and neoliberal state, at this point understanding the intersections between Law and Economics focusing on the autonomization or not of legal and economic orders. Next, it analyzes the characteristics of the economic models of Welfare State and Neoliberalism. Finally, it studies the legal-economic model of the Federal Constitution of 1988, from the perspective of the theoretical framework studied. The research adopts the bibliographical and documentary technical procedures and is traced by the hypothetical-deductive method, concluding true the hypothesis provisionally raised that although the constitutional text has offered the proposal of a social-democratic welfare, in practice a neoliberal agenda became effective as a result of international pressures that took force in globalized times, in the midst of consolidation processes of a conservative and corporatist welfare, which serves only to justify state enlargement and not to reduce inequalities. The methodology adopted is the bibliographical and documentary review with the use of the deductive method. The thoughts of Adam Smith and Keynes lead the line of argument of the article.

Keywords: Welfare State. Globalization. Neoliberalism. State intervention in the economy.

\section{SUMÁRIO}

1 Introdução. 2 Da pretensa autonomização entre as ordens jurídica e econômica à consolidação de um modelo intervencionista. 3 A intervenção do Estado na economia ante os modelos do estado de bem-estar social e do estado neoliberal. 4 Análise do modelo jurídico-constitucional brasileiro de intervenção na economia diante das características dos modelos do estado de bem-estar social e do estado neoliberal. 5 Considerações finais. 6 Referências. 


\section{INTRODUÇÃO}

Compreender as intersecções entre Direito e Economia na história da modernidade não é tarefa fácil. Muitos teóricos se engajaram na missão de responder à pergunta-chave que colocaria ponto final nas controvérsias teóricas: Afinal, qual a medida de intervenção estatal na economia, necessária e suficiente, para promover o crescimento econômico sem prejudicar a fruição de direitos fundamentais?

Nesta vertente, surgem duas grandes teorias econômicas, que são analisadas em termos históricos e teóricos na primeira parte do artigo: a liberal clássica, encabeçada por Adam Smith (1996), e a social, liderada por John Maynard Keynes. Sob estas perspectivas, analisa-se como estas teorias concebiam a relação entre a ordem econômica e a ordem jurídica, justificando abstenção ou intervenção estatal.

Tais teorias econômicas evoluíram e se adaptaram no contexto da pós-modernidade globalizada, dando origem, de um lado, ao modelo do Welfare State, inspirado na teoria keynesiana, e, de outro, ao modelo de Estado Neoliberal, proposto na tentativa de reavivar o capitalismo clássico, estritamente liberal e não intervencionista. $O$ estudo das características destes novos modelos é feito na segunda parte deste artigo.

Assim sendo, busca-se, finalmente, com fundamentação no referencial teórico levantado, compreender como se opera no Brasil o fenômeno do neoliberalismo periférico no contexto da economia globalizada, concentrando-se na análise do modelo jurídico-econômico da Constituição Federal de 1988, notadamente compreendendo os princípios que norteiam as bases da ordem econômica e financeira e da ordem social, e, de forma derradeira, analisando a composição teórica do fenômeno do neoliberalismo periférico globalizado.

Com efeito, procura-se responder ao seguinte problema de pesquisa: Existe compatibilidade entre o modelo econômico proposto pela constituinte de 1988 e o modelo econômico efetivamente adotado a partir do advento constitucional?Adotando os procedimentos técnicos bibliográfico e documental, traçado pelo método hipotético-dedutivo, o artigo traz como resposta provisória ao problema a afirmação de que é incompatível a proposta altamente protetiva da Constituição de 1988, que, tipicamente, caracteriza um modelo de Welfare State, com a agenda neoliberal imposta aos países periféricos da América Latina em tempos de globalização.

\section{DA PRETENSA AUTONOMIZAÇÃO ENTRE AS ORDENS JURÍDICA E ECONÔMICA À CONSOLIDAÇÃO DE UM MODELO INTERVENCIONISTA}

Das origens ao contexto atual, muito se desenvolveram as teorias econômicas e, no mesmo compasso, transformaram-se as noções que cercam a relação entre Economia e Direito. Neste ponto, nota-se que esta relação é mais intensa quanto maior a margem para as políticas de intervenção estatal. Em outras palavras, quanto mais o Estado se propõe a intervir na Economia, fazendo-o pela via da regulação, menos se percebe uma clara distinção entre a ordem econômica e a ordem jurídica. A grande pergunta que as teorias econômicas buscam responder passa a ser: Qual a medida suficiente e adequada de intervenção estatal que não prejudique o bom andamento das atividades econômicas?

Quando emergiram as primeiras teorias econômicas, firmou-se a ideia de que a ordem econômica era uma ordem natural, verdadeiramente autônoma, que guiaria seus próprios rumos de forma adequada caso fosse deixada livre. Neste viés, os fisiocratas, que desenvolveram seus conceitos num contexto que, apesar de agrário, já era de ordem capitalista (afirmando a teoria do excedente), reconheciam:

Ao contrário do que ocorre no âmbito da natureza física, a sociedade pode encontrar-se distanciada de sua própria "ordem", definida como "natural", apenas no sentido de que, se os homens não obstaculizarem o livre desenvolvimento das diversas forças que operam na sociedade, a sociedade tenderá a configurar-se segundo um desenho necessário, e passará a funcionar segundo leis que se impõem automaticamente a todos (NAPOLEONI, 2000, p. 19).

O elemento de natureza econômica se manifestaria como a base da constituição da ordem social natural, considerando que as leis que regem a sociedade são necessárias apenas para viabilizar o exercício da atividade econômica e para nada mais, cabendo à economia, sozinha, propiciar a melhoria na fruição das necessidades sociais. 
O efeito de melhoria na fruição seria automático e não guiado pela regulação, sendo esta uma premissa que decorre do próprio caráter natural da ordem: "O caráter natural dessa ordem deriva do fato de que sua instauração deveria ocorrer automaticamente, em razão das mesmas forças sociais em jogo, uma vez que falsas regras de governo não impediriam que tais forças explicassem sua própria natureza" (NAPOLEONI, 2000, p. 32).

Mais tarde, economistas e juristas desenvolveram a noção de ordem social autônoma para explicar o fenômeno da intervenção do Direito na Economia, caracterizando a Economia como uma ordem social com regulamentação própria (autorregulamentação), que funcionaria à parte da tradicional ordem social imposta pelo controle estatal.

Numa ordem social, as circunstâncias particulares para as quais cada indivíduo irá reagir serão aquelas conhecidas por ele. Mas as respostas individuais a circunstâncias particulares irão resultar numa ordem geral apenas se os indivíduos obedecerem tais regras que irão produzir uma ordem (tradução nossa) (HAYEK, 1998, p. 44). ${ }^{1}$ Hayek (1998), conhecido como um dos pensadores que lançou bases ao neoliberalismo, desenvolveu sua teoria sobre a economia como uma ordem social autônoma, reconhecendo que existe uma complexidade no processo de formação destas, decorrente, principalmente, da capacidade de autorregularem-se, de forma que a ordem social autônoma seria formada por regras, não por caos.

Não se pretende afirmar que a ordem social autônoma seja ocupada por regras expressas e fechadas, elaboradas em cada situação mínima de conflito. Muitas vezes, tais regras serão essencialmente amplas, tal como o seriam as da economia, que passariam alheias ao controle estatal - que, caso se fizesse impor, tenderia à inocuidade. A presença, entretanto, de regras que sejam minimamente seguidas pelas pessoas, é essencial para que a ordem social formada seja benéfica a elas (HAYEK, 1998).

Além disso, não se pode negar que as circunstâncias que cercam o processo de formação de uma ordem social autônoma são complexas.

Desde que uma ordem espontânea resulte de elementos individuais adaptando-se uns aos outros a circunstâncias que diretamente afetam apenas alguns deles, e que em sua totalidade não precisam ser conhecidos por qualquer um, isto pode estender a circunstâncias tão complexas que não poderão ser compreendidas pela mente (tradução nossa) (HAYEK, 1998, p. 41). ${ }^{2}$

Percebe-se que a teoria sobre a ordem social natural foi aprofundada no futuro de modo a reconhecer a necessidade de regulação, embora tal regulação não necessariamente viesse pelas vias tradicionais da norma posta pelo Estado. Assim, convergem os liberais e os neoliberais ao afirmar que a atividade regulatória não deve retirar o caráter essencialmente livre atribuído à economia enquanto ordem autônoma.

Voltando à perspectiva histórica do constructo teórico liberal, no esteio dos fisiocratas, Adam Smith foi o primeiro pensador a elaborar um modelo abstrato e completo, focado em explicar o sistema capitalista contextualizado na Revolução Industrial inglesa, desenvolvido na obra A Riqueza das Nações (SMITH, 1996).

Havia nas "leis da natureza" ou na "divina providência", o que Smith chamava de "mão invisível", que guiava esses atos, que aparentemente provocavam conflitos, de modo a haver mais harmonia. A "mão invisível" não era fruto do desígnio de qualquer indivíduo. Era, simplesmente, o funcionamento sistemático de leis naturais. Essa é, inquestionavelmente, a maior incongruência - senão a maior contradição - da obra de Smith. Pode-se encontrar a mesma contradição na obra de David Ricardo (HUNT, 2005, p. 41).

A teoria da "mão invisível" de Smith se associa diretamente à perspectiva de que a economia apenas é motriz da ordem natural das coisas, afirmando-se que, ao deixar que as leis naturais ordenem as atividades econômicas, se obterá a maior riqueza, sendo, portanto, prejudicial ao bem-estar econômico qualquer intervenção do Estado neste regular andamento.

\footnotetext{
No original: "[...] in a social order the particular circumstances to which each individual will react will be those known to him. But the individual responses to particular circumstances will result in an overall order only if the individuals obey such rules as will produce an order".

2 No original: "Since a spontaneous order results from the individual elements adapting themselves to circumstances which directly affect only some of them, and which in their totality need not be known to anyone, it may extend to circumstances so complex that no mind can comprehend them all".
} 
No contexto da teoria da História, de Smith, o capitalismo representava o estágio mais alto de civilização e atingiria seu ponto culminante, quando tivesse evoluído para um estado em que o governo tivesse adotado uma política de laissez-faire, permitindo que as forças da concorrência e o livre jogo da oferta e da demanda regulassem a economia, que ficaria quase que completamente livre das restrições do governo ou de suas intervenções. [...] Smith rejeitou teorias e políticas, tanto dos mercantilistas como dos fisiocratas, e depois indicou qual era o sistema que maximizaria o bem-estar econômico. Essa afirmação é a principal conclusão do livro: o capitalismo laissez-faire ou, conforme Smith o chamava, "o sistema óbvio e simples de liberdade natural", é afirmado como o melhor sistema econômico possível. [...] Descrevendo o fluxo de capital para a indústria interna num "sistema de liberdade natural", Smith formulou a proposição mais famosa de sua tese, segundo a qual em um mercado livre os atos egoístas dos indivíduos são dirigidos, como que por uma "mão invisível", para a maximização do bem-estar econômico (HUNT, 2005, p. 54-56).

A teoria da mão invisível de Smith pressupõe a existência de mercados em concorrência perfeita, caracterizada sempre que houver um grande número de vendedores e de compradores, e nenhuma empresa sozinha conseguir influenciar os índices de demanda e, por conseguinte, o preço natural. Num contexto de concorrência perfeita, é simples presumir a eficácia de uma teoria da mão invisível, entretanto não é possível fechar os olhos ao fato de que a concorrência, cada dia mais, notadamente diante do gigantismo empresarial que flui em tempos globalizados, em regra é imperfeita.

Coase (1937) reconhece que há clara distinção estrutural entre um mercado que opere em concorrência perfeita e um que opere em concorrência imperfeita, o que é determinante de forma mais evidente, embora não exclusivamente, em virtude do mecanismo de preços utilizado em cada um dos modelos. Enquanto na concorrência perfeita o modelo de preços em essência é determinado pelos fluxos do mercado de oferta e demanda, na concorrência imperfeita o comportamento dos agentes de mercado pode se alterar no sentido de buscar, por meio de colusão e de outras formas, influenciar no que seria o preço natural de mercado, atentando contra as prerrogativas do consumidor e afetando seu bem-estar.

A sequência de eventos históricos que seguiram ao apogeu da teoria de Smith desmereceu por si a ideia de que a Economia tem o poder de, pelas suas leis naturais, somente coibir os comportamentos abusivos e danosos dos agentes econômicos. Em meio a um contexto de intensas lutas decorrentes do surgimento da consciência de classe e de ruptura com o modelo capitalista como o único modelo econômico possível, entra em decadência o Estado Liberal e ascende o Estado Social.

A teoria econômica predominante, na época, é a teoria neoclássica, principalmente em sua versão marshalliana. Essa teoria tem como suposto a "lei de Say", segundo a qual o processo de produção capitalista é, também, um processo de geração de rendas (licros, salário, aluguéis, etc.) e, por isso, a oferta cria sua própria demanda. Acrescente-se a isto a ideia de ajustamento automático da economia e teremos uma conclusão importante: o sistema econômico, considerado como um todo, não pode admitir desemprego involuntário. Trata-se de uma decorrência natural dos supostos anteriores. Se desemprego houver, ele será temporário, esporádico e parcial. Esta a posição teórica da principal corrente econômica da época. A realidade dos fatos desmentia a teoria (ARAÚJO, 1988, p. 110).

Com o desemprego involuntário se tornando uma realidade, os neoclássicos ainda buscavam afirmar a adequação de suas teorias, que somente eram úteis nos contextos de mercados perfeitos - e naquele momento já se percebia a estruturação de modelos de mercado imperfeito em monopólios e oligopólios. Tal contradição teórica clara abriu margem para a chamada revolução keynesiana, em que se defendia a necessidade de intervenção do Estado na economia, afastando o ideal da concorrência perfeita e confrontando diretamente a composição teórica da época ante a realidade fática (ARAÚJO, 1988).

Para Keynes (1996), o nível de emprego seria determinado pelo nível de produção, o qual, por sua vez, seria determinado pela demanda efetiva, ora composta por bens de consumo, bens de investimento e gastos públicos, quando a renda seria determinada pelos gastos em consumo e pelos gastos em investimento, mas, principalmente, pelo segundo aspecto (ora claramente determinado a partir dos gastos públicos), uma vez que o consumo tende a ser estável. Este seria o princípio da demanda efetiva, a maior contribuição de Keynes à teoria econômica. 
Diferente dos neoclássicos, Keynes (1996) defende que é preciso fazer controle quanto à capacidade de consumo, melhorando o poder aquisitivo da população, e investir em aumento de produção, o que geraria, então, crescimento econômico. A teoria de Keynes era a morte para o ideal de laissez-fair do liberalismo clássico, pois reconhecia, de forma clara, a incapacidade do mercado de, sozinho, conseguir gerar uma demanda ideal. Expõe Keynes (1996, p. 43):

Os postulados da teoria clássica se aplicam apenas a um caso especial e não ao caso geral, pois a situação que ela supõe acha-se no limite das possíveis situações de equilíbrio. Ademais, as características desse caso especial não são as da sociedade econômica em que realmente vivemos, de modo que os ensinamentos daquela teoria seriam ilusórios e desastrosos se tentássemos aplicar as suas conclusões aos fatos da experiência.

Na sua visão, a demanda efetiva poderia ser maior ou menor que a capacidade produtiva de um país em um determinado momento, podendo haver desemprego de fatores produtivos. Abre-se espaço, então, para que o Estado, mediante mobilização da vontade política, desenvolva políticas econômicas voltadas à realização da demanda efetiva, de modo a intervir na economia com políticas monetária e fiscal que afetam diretamente os fatores consumo e investimento e mediante controle dos gastos públicos, que, por seu turno, afetam a tributação. Neste ponto, o Estado assume para si o papel de controlar juros e a própria taxa de inflação, bem como de direcionar pela tributação a entrada de investimentos no mercado econômico.

Ao desaparecer o dogma da mão invisível, o espaço abre-se para a política, especialmente para a política monetária e a política fiscal. A política monetária é importante, em determinadas circunstâncias, principalmente na determinação da taxa de juros. Contudo, quando a taxa de juros se aproxima da armadilha da liquidez, ela perde eficácia. A política fiscal compõe-se de uma série de expedientes relativos à tributação e aos gastos governamentais (ARAÚJO, 1998, p. 132).

A abertura que Keynes propiciou para a intervenção do Estado na economia influenciou a política econômica de diversos países capitalistas. De forma diversa do esperado pelo teórico, entretanto, os Estados não souberam manejar de forma adequada os poderes que lhe foram postos, demonstrando-se, ao longo da história, como incapazes de controlar de forma coerente os gastos públicos e de intervir de maneira equilibrada na economia. Em vez de crescimento econômico, os excessos de intervenção autorizados pelo modelo keynesiano geraram a consolidação de economias de guerra e incalculáveis déficts orçamentários.

Era necessário modernizar as teorias econômicas postas até o momento, amadurecendo seus aspectos centrais que se mostraram falhos. Nesta perspectiva, a proposta de Keynes foi aperfeiçoada num modelo de Welfare State; enquanto a proposta liberal clássica ganhou novos rumos com o modelo neoliberal. Uma maior análise do modelo do Welfare State e neoliberal é apresentada no tópico a seguir.

\section{A INTERVENÇÃO DO ESTADO NA ECONOMIA ANTE OS MODELOS DO ESTADO DE BEM-ESTAR SOCIAL E DO ESTADO NEOLIBERAL}

Considerando a estruturação de dois grandes modelos econômicos que prevaleceram nos Estados ao longo do último século, cabe analisar quais as premissas destes no que se refere ao papel do Estado na economia. Neste campo, parte-se da influência do modelo de Keynes no Welfare State até chegar à decadência deste para a ascensão do Neoliberalismo.

O Estado de Bem-Estar Social ou Welfare State pode ser visto como a forma mais avançada de exercício público da proteção social. Fiori (1995) explica que o Welfare contemporâneo está centrado em quatro pilares: o primeiro, que são os fatores materiais ou econômicos que englobam o reconhecimento de valores como crescimento e pleno emprego, a manutenção do crescimento econômico, o aumento dos ganhos fiscais, algum consenso paralelo quanto às políticas de Keynes e a generalização do paradigma fordista; o segundo, que é o ambiente econômico global criado que permitiria conciliar o Welfare e a estabilidade da economia internacional; o terceiro, que é o clima de solidariedade nacional entre países vencedores e vencidos no pós-Segunda Guerra; o quarto, que é o avanço das democracias partidárias e de massa, que geraram efetiva disputa eleitoral e, assim, abriram margem às reivindicações de diversos setores sociais. 
A primeira característica que pode ser atribuída a este modelo consiste na adoção de novas formas de política social, muito diversas das que Ihe precederam, historicamente, notadamente antes da Segunda Guerra Mundial. Sobre esta característica, Fiori (1995, p. 4) afirma:

Não cabem dúvidas que só os estudos mais recentes propuseram um conceito capaz de dar conta da complexidade do fenômeno do welfare e, portanto, também, de suas diferenças e descontinuidades fundamentais com as trajetórias e/ou padrões históricos anteriores, de organização das políticas sociais de tipo privado ou governamental, assistencial ou contratual.

A compreensão do fenômeno do Welfare State depende aqui, também, da percepção acerca dos entrelaçamentos das atividades estatais com o papel do mercado e da família. Neste viés, não basta observar a característica que consiste na adoção de novas formas de política pública, mas é preciso considerar as efetivas mudanças regulatórias que atingem os serviços sociais universais e a própria distribuição de renda como objetivo estatal.

De forma mais específica, cabe observar diversos modelos de Welfare, com características próprias, variando entre países e regiões do mundo.

Conforme Fiori (1995), há diversas classificações, mas, de forma geral, pode-se apresentá-las da seguinte forma:

a) Residual ou liberal: políticas sociais sem caráter preventivo e temporariamente limitadas, normalmente aos comprovadamente pobres;

b) Meritocrático-particularista ou conservador-corporativista: política social usada apenas para corrigir a ação do mercado, atuando de forma complementar, pouco esforço em direção a uma redistribuição;

c) Institucional-redistributivo ou socialdemocrata: voltado para a produção e distribuição de bens e serviços sociais, garantidos a todos os cidadãos de forma universal.

Com efeito, o modelo de Estado de Bem-Estar Social entrou em decadência nos anos 70, conforme os Estados que adotavam tais formatos ficavam cada vez mais extensos, pesados e onerosos. Isso gerou graves reflexos durante as crises econômicas que avançaram pelo mundo a partir deste período.

O Welfare passou a ser colocado como um dos principais fatores nos diagnósticos de crises, mas o seu desmonte não se deu de forma abrupta e estrondosa e, na verdade, ainda é possível perceber traços dele na economia de diversos Estados - mesmo naqueles que atendem, hoje, a uma agenda predominantemente neoliberal. Com a globalização, entretanto, intensificou-se o desmonte dos modelos de Welfare.

Especificamente quanto à ascensão do Neoliberalismo, Anderson (1995, p. 9) analisa:

O neoliberalismo nasceu logo depois da II Guerra Mundial, na região da Europa e da América do Norte onde imperava o capitalismo. Foi uma reação teórica e política veemente contra o Estado intervencionista e de bem-estar. Seu texto de origem é O Caminho da Servidão, de Friedrich Hayek, escrito já em 1944. Trata-se de um ataque apaixonado contra qualquer limitação dos mecanismos de mercado por parte do Estado, denunciadas como uma ameaça letal à liberdade, não somente econômica, mas também política.

Hayek juntou-se a outros fortes críticos do New Deal americano e do Estado de Bem-Estar europeu, como Milton Friedman, Karl Popper, Ludwig Von Mises, entre outros, e fundou a Sociedade de Mont Pèlerin, cujo propósito era combater as ideias de Keynes ora dominantes e lançar bases para um novo tipo de capitalismo. Embora a formação do ideário neoliberal tenha se dado no entorno do final da Segunda Guerra, somente com as crises financeiras da década de 70, cercadas pela baixa taxa de crescimento e pela alta taxa de inflação, ele começou a ganhar terreno (ANDERSON, 1995).

Em termos característicos, o modelo neoliberal tem como algumas de suas premissas em relação ao modelo de welfare: remercantilização da força de trabalho, contenção ou desmontagem de sindicatos, desregulação de mercados de trabalho, privatização de serviços sociais, cortes nos programas de integração de renda, maior autonomia e poder a setores voluntários e outras organizações privadas ou filantrópicas (FIORI, 1995). 
Algumas políticas econômicas típicas de um modelo neoliberal podem ser observadas a partir do governo de Thatcher na Inglaterra: contração da emissão monetária, elevação da taxa de juros, redução dos impostos de alto rendimento, abolição de controle dos fluxos financeiros, criação de níveis massivos de desemprego, combate a greves, corte de gastos sociais, criação de legislação antissindical e, principalmente, engajamento num forte programa de privatizações (ANDERSON, 1995).

Nem todos os países, no entanto, se engajaram em medidas tão radicais na época; por exemplo, alguns governos de direita europeus optaram por tornar mais criteriosa a disciplina orçamentária e por engajar reformas fiscais, em vez de confrontar sindicatos e reduzir gastos sociais num modelo neoliberal moderado (ANDERSON, 1995).

Denomina-se de decálogo neoliberal o composto de dez características essenciais do modelo neoliberal da economia:

1. O Estado tem que limitar sua atuação ao estritamente imprescindível.

2. As contas do setor público devem estar sempre equilibradas.

3. Eliminar subsídios a empresas, cortar os gastos sociais e reduzir ao mínimo os gastos correntes da Administração.

4. Corte drástico dos impostos e encargos sociais de empresas e particulares.

5. Flexibilidade do mercado de trabalho. Eliminação do salário mínimo.

6. Reformas estruturais pela via de uma maior flexibilidade do mercado fundiário e uma abertura geral à concorrência.

7. Políticas microeconômicas de fomento ao investimento privado e políticas ativas de emprego.

8. Políticas monetárias baseadas em tipos de interesses baixos.

9. Política fiscal que incentive o reinvestimento de benefícios.

10. Modificação do sistema de negociação coletiva (PÉREZ GÓMEZ, 2001, p. 128-129).

Anderson (1995) diagnostica que, quanto ao objetivo de travar o aumento incontrolável dos índices de inflação, o neoliberalismo foi bem-sucedido, mas não conseguiu alcançar o seu principal objetivo, que era a restauração do crescimento econômico. Logo,

[...] a recuperação dos lucros não levou a uma recuperação dos investimentos. Essencialmente, pode-se dizer, porque a desregulamentação financeira, que foi um elemento tão importante do programa neoliberal, criou condições muito mais propícias para a inversão especulativa do que produtiva. [...] Por outro lado, o peso do Estado de Bem-Estar não diminuiu muito, apesar de todas as medidas tomadas para conter os gastos sociais (ANDERSON, 1995, p. 16).

Em que pese o neoliberalismo não ter alcançado os resultados esperados, isso não significou a sua morte. Pelo contrário, o projeto neoliberal até hoje possui impressionante vitalidade, mesmo que, no fundo, tenha propiciado mais a construção de sociedades desiguais do que alheias à intervenção estatal, como havia proposto.

O que se percebe, em todo o globo, é a consolidação de modelos de Estado de clara influência neoliberal, mas que não rompem laços definitivos com o modelo precedente, de Welfare State. De forma generalizada, características neoliberais marcantes, como a abertura de mercado e a desregulação da atividade econômica, se fazem presentes, mas sem implicar a necessária redução da máquina estatal, cada vez mais complexa e burocrática, que utiliza o discurso de manutenção de práticas do Estado de Bem-Estar - sem necessariamente efetivá-lo - como uma justificativa para seu constante agigantamento.

A formação deste modelo misto não atinge o objetivo de afastar a intervenção estatal; pelo contrário, aparatos cada vez mais burocráticos se instalam, e muito menos o de propiciar efetivo bem-estar social, pois o agigantamento dos mercados não precisamente reflete numa ampliação dos investimentos do poder público. Cada dia mais, entretanto, o cenário parece se consolidar de forma irreversível, em especial em razão das consequências da globalização. 
Neste ponto, globalização e neoliberalismo são contos da mesma fábula, que consolida a noção de economia-mundo. Nessa nova concepção de trocas, fixos e fluxos, o Estado submete-se aos interesses transnacionais, tanto produtivos quanto especulativos, em nome de uma promessa de crescimento e modernização que nunca se cumpre. A globalização cobra seu preço, mensurado em exigências político-econômicas neoliberais (LEME, 2010).

As Reformas implicaram a solicitação de novos arranjos político-institucionais para se ajustarem a novos desafios, muito deles, visando à sinergia maior entre a "esfera" nacional às demais demandas/pressões da "esfera" global. Esse processo reflete diretamente na forma dos atores conceberem o Estado e suas diversas funções, sejam elas no campo econômico, político ou cultural (LEME, 2010).

A globalização mostra-se um processo histórico de produção e reprodução do capital de forma combinada e desigual que, ao mesmo tempo em que visa a integrar, também salienta as diferenças, sejam elas culturais, sociais, políticas, econômicas e espirituais entre os países do Norte e do Sul. Se, por um lado, promete integração, na verdade entrega polarização - e mesmo as promessas de cooperação internacional, tão largamente afirmadas na construção do sistema de proteção de direitos humanos, pouco se efetivam. Neste ponto, o neoliberalismo globalista periférico desponta como um cenário desolador.

\section{ANÁLISE DO MODELO JURÍDICO-CONSTITUCIONAL BRASILEIRO \\ DE INTERVENÇÃO NA ECONOMIA DIANTE DAS CARACTERÍSTICAS DOS MODELOS DO ESTADO DE BEM-ESTAR SOCIAL E DO ESTADO NEOLIBERAL}

A base do modelo jurídico-constitucional brasileiro de intervenção na economia encontra-se no título VII da Constituição Federal, intitulado "Da Ordem Econômica e Financeira", que conta com quatro capítulos: princípios gerais da atividade econômica, política urbana, política agrícola e fundiária e reforma agrária e sistema financeiro nacional.

Vale analisar, neste ponto, o artigo 170 do texto constitucional:

Art. 170. A ordem econômica, fundada na valorização do trabalho humano e na livre iniciativa, tem por fim assegurar a todos existência digna, conforme os ditames da justiça social, observados os seguintes princípios:

I- soberania nacional;

II - propriedade privada;

III - função social da propriedade;

IV - livre concorrência;

$\mathrm{V}$ - defesa do consumidor;

$\mathrm{VI}$ - defesa do meio ambiente, inclusive mediante tratamento diferenciado conforme o impacto ambiental dos produtos e serviços e de seus processos de elaboração e prestação;

VII - redução das desigualdades regionais e sociais;

VIII - busca do pleno emprego;

IX - tratamento favorecido para as empresas de pequeno porte constituídas sob as leis brasileiras e que tenham sua sede e administração no País.

Parágrafo único. É assegurado a todos o livre exercício de qualquer atividade econômica, independentemente de autorização de órgãos públicos, salvo nos casos previstos em lei.

O constituinte brasileiro tenta trazer, no artigo 170, um equilíbrio entre a liberdade econômica e a necessidade de intervenção estatal em prol da preservação do interesse coletivo e individual. Assim, se por um lado coloca o direito à propriedade, por outro fixa o dever de obediência à sua função social; se por um lado coloca a livre-iniciativa e a livre-concorrência, por outro as limita pelas necessidades de atendimento a interesses, como busca do pleno emprego (ideário típico de um Estado de Bem-Estar, pois no neoliberalismo vai se pregar que algum desemprego é necessário à economia), redução de desigualdades regionais e sociais (outra política própria de welfare), defesa do meio ambiente (aspecto de dimensão difusa, ligado à questão da fraternidade como direito) e tratamento favorecido a empresas de pequeno porte nacionais (mais uma vez, algo típico de welfare, pois irá pressupor a oferta de subsídios e vantagens a atividades empresariais que, de 
outra forma, teriam de se desenvolver por si). Não obstante, se de um lado fixa que o Estado, como agente normativo e regulador da atividade econômica, não deve, em regra, ser também seu explorador, abre diversas exceções os casos de necessidade aos imperativos da segurança nacional ou relevante interesse coletivo (artigo 173, caput, CF) - expressões estas tão amplas que acabam sendo interpretadas pelo próprio administrador num critério completamente discricionário - e inclusive cria situações de monopólio da União sobre determinadas atividades econômicas (artigo 177, CF).

Nota-se que o constituinte brasileiro parece mais preocupado em criar limites à liberdade de iniciativa e de concorrência do que em viabilizá-las, o que põe em xeque se a realização destas era a sua verdadeira intenção. Técnica e historicamente, o constituinte brasileiro sempre pareceu mais preocupado em assumir controle sobre todas as coisas, inclusive sobre o próprio mercado. Não obstante, a leitura do texto constitucional leva a perceber, de forma clara, que toda liberdade deve ser limitada se não promover o bem-estar e a justiça sociais.

Com efeito, não é possível ler a disciplina da ordem econômica sem se atentar à previsão constitucional sobre a ordem social, que deve se harmonizar com a disciplina da ordem econômica. A propósito, prevê o artigo 193, CF: "a ordem social tem como base o primado do trabalho, e como objetivo o bem-estar e a justiça sociais". De fato, o constitucionalista brasileiro, nos artigos que se seguem, direciona um comprometimento com a efetivação do bem-estar e da justiça sociais de forma integral e universal. Neste sentido, destacam-se as previsões específicas sobre o direito à educação e o direito à saúde, guiados pelo ditame da universalidade, do acesso integral e da gratuidade.

Pela simples leitura da Constituição, percebe-se que é claramente assumido um compromisso constitucional que mais tende ao welfare do que ao neoliberalismo, ainda que a década de 80, quando o texto brasileiro foi elaborado, já fosse um período no qual globalmente o Welfare State já havia sido desacreditado, dando lugar ao modelo neoliberal que, àquela altura, sem sucumbir às crises dos anos 90 , ainda parecia ser o mais promissor.

O Brasil, tal como tantos outros países, acabou por ficar no intermédio entre o welfare e o neoliberalismo. Embora o constituinte brasileiro tenha sido influenciado pelo ideário neoliberal, acabou por trazer no texto escrito da norma constitucional, tipicamente dirigente, amplas normas de proteção que se aproximam do mais marcante dos modelos de Welfare State, que seria o institucional-redistributivo, conforme a teoria de Titmus, ou socialdemocrata, pela teoria de Esping-Andersen. Referidos modelos propunham um Estado de Bem-Estar Social praticamente irrestrito, de amplo acesso a todos os bens e os serviços sociais de forma universal e integral, apenas tendo se consolidado, ironicamente, nos países escandinavos e na Suécia. Promessas à parte, o welfare brasileiro real está muito longe de um modelo socialdemocrata ou institucional-redistributivo.

Fiori (1995) mostra que, embora os modelos de welfare variem entre os países, a diferença é mais gritante quando se observa o welfare nas periferias capitalistas, especialmente as latino-americanas. Quanto às tipologias apontadas, o autor observa que nenhuma se aplica puramente às periferias capitalistas, embora exista alguma aproximação do modelo meritocrático-particularista de Titmus e do modelo conservador e corporativista de Esping-Andersen com relação ao modelo econômico brasileiro - de toda forma, uma realidade que se distancia em absurdos da proposta constituinte. De modo mais específico, diversos estudos procuram avançar na compreensão do que seria o padrão periférico de política social.

De tal maneira que a discussão dos casos periféricos latino-americanos deve inevitavelmente deslocar-se para matizes com que se combina em cada país o assistencialismo e as intervenções tópicas de tipo liberal com alguns sistemas universais de prestação de serviços de preservação ou mesmo complementação da renda (FIORI, 1995, p. 10).

O trecho bem-descreve a realidade brasileira, em que, de um lado, busca-se seguir aos anseios das pressões internacionais de cunho neoliberal, mas de outro, luta em efetivar algumas poucas e raramente efetivas políticas assistenciais que pretendem lançar sistemas universais de serviços públicos (educação e saúde são os maiores exemplos disso) e que buscam complementar a renda da população de classe mais baixa. 
Um financiamento regressivo do gasto social e uma hipertrofia burocrática que eleva em muito o custo operacional e favorece a manipulação clientelística. Um welfare state, em síntese, meritocrático-particularista fundado na capacidade contributiva do trabalhador e num gasto público residual financiado por um sistema tributário regressivo. Um sistema não-redistributivo e montado sobre um quadro de grandes desigualdades e de misérias absolutas (FIORI, 1995, p. 11-12).

No real Welfare State brasileiro, tipicamente periférico, se faz presente um Estado agigantado e excessivamente burocrático que se justifica sob a pretensão de ser o responsável por efetivar a vontade do constituinte de criar bem-estar, mas, na realidade, subjuga a liberdade e a vontade do cidadão brasileiro, sujeito a uma carga tributária predominantemente incidente sob o consumo, que retira todo seu poder de compra e que pouco retorna ao povo o que arrecada, bem como ao alvedrio do setor empresarial globalista, que foge às inúmeras e incansáveis tentativas de regulação e controle. O Estado, assim, não apenas não consegue cumprir seu papel de intervenção na economia, como adiciona um fator negativo à equação que, por si só, não teria solução favorável.

Com efeito, embora vitorioso teoricamente na Constituição, o modelo de Welfare State deu lugar, no Brasil, ao modelo Neoliberal. Neste ponto, o Brasil foi o último dos países da América Latina a atender esta agenda internacional, notadamente pela dificuldade anterior aos anos 90 de conciliar as frações de classe do bloco dominante e se desvencilhar dos interesses da mobilização política dos trabalhadores. Nos anos 90,0 liberalismo,

[...] que já havia adentrado na maior parte da América Latina, implanta-se no Brasil, com toda força, a partir do Governo Collor. O discurso liberal radical, combinado com a abertura da economia e o processo de privatizações inaugura o que poderíamos chamar da "Era Liberal" no Brasil. Até então, apesar da existência de algumas iniciativas nesse sentido, durante o Governo Sarney, e de uma já forte massificação e propaganda dessa doutrina nos meios de comunicação de massa, havia uma forte resistência à mesma, calcada principalmente, na ascensão política, durante toda a década de 1980, dos movimentos sociais e do movimento sindical. A Constituição de 1988, apesar de seus vários equívocos, foi a expressão maior dessa repulsa da sociedade brasileira, por isso mesmo, ela foi alvo privilegiado tanto do Governo Collor quanto do Governo Cardoso, que recolocou, mais tarde, o projeto liberal nos trilhos (FILGUEIRAS, 2000, p. 83-84).

Este projeto brasileiro foi marcado de forma clara pela globalização, não apenas pelo ingresso de empresas estrangeiras no país, muitas vezes assumindo a administração de empresas que então estavam sob o controle do Estado, mas também pela internacionalização dos grandes grupos empresariais brasileiros. Cada vez mais a economia brasileira estaria sujeita aos fluxos internacionais de capitais. Mesmo quando as então classes opostas ao projeto neoliberal chegaram ao poder com o governo Lula, evitou-se qualquer confronto com o bloco dominante e mantiveram-se iniciativas do modelo neoliberal, agora consolidado (FILGUEIRAS, 2006, p. 179-206).

Não é possível, assim, negar a estrita relação dos entraves à efetivação de um modelo de welfare crescentemente socialdemocrata no Brasil (com pretensão de universalidade e cobertura integral de serviços públicos essenciais), que era a intenção do constituinte de 1988, com a imposição externa da ideologia neoliberal. Ao ceder às pressões internacionais, o Brasil foi colocando entre os países sujeitos ao neoliberalismo periférico, essencialmente prejudicial e danoso.

A adoção do neoliberalismo jogou a América Latina nas profundezas do crasso subdesenvolvimento, periferizando ainda mais as precárias economias e relações societais no sistema-mundo. Neste processo houve uma deterioração das condições sociais de vida com o agravamento da pobreza, do desemprego, da precarização das relações de trabalho, do aumento das desigualdades internas etc. apesar dos recentes avanços em termos de redução da pobreza e da indigência. Pelo ideário neoliberal, a liberalização do sistema financeiro, a flexibilização da taxa de câmbio e a estabilização monetária - requisitos fundantes para o sucesso do modelo, entre outros - impeliram algumas economias regionais a um crescimento significativo. Entretanto, com a abertura econômico-financeira as fragilidades estruturais - estruturas, historicamente, atrasadas e subdesenvolvidas não suportaram os impactos competitivos e ataques concorrenciais, exigências decorrentes das novas regras estabelecidas pela Organização Mundial do Comércio (OMC). A euforia inicial se esvanece frente à escassez interna de recursos financeiros e de investimentos, na medida em que o capital estrangeiro fluía no passado, sob a proteção dos regimes militares e no início da adoção neoliberal pelas privatizações das empresas estatais dos 
diferentes ramos da economia e do sistema financeiro. Na economia globalizada o sistema-mundo capitalista vive e sobrevive na e com a especulação financeira. Assim, as economias latino-americanas não resistiram aos diferentes "ataques" especulativos e suas perversas sequelas (PETRY, 2007, p. 23).

O neoliberalismo periférico é um fenômeno socioeconômico que decorre da agenda econômica em tempos globalizados. Trata-se da imposição do neoliberalismo como modelo econômico a todos os países periféricos, que, caso não atendida, gera consequências ainda mais severas, consubstanciadas na forma de isolamento econômico - mais difícil de ser suportada quanto mais as economias em todo o mundo passam a se sujeitar aos fluxos internacionais.

Ocorre que a globalização, compreendida como um fenômeno de integração social, cultural, econômica, religiosa, etc., diferente do que se pretende passar, não é uniforme, podendo se notar a caracterização de polos globalizados e polos marginalizados.

Conforme Boaventura de Sousa Santos (2001), a globalização é, na realidade, um processo de simultâneas globalizações de elementos locais; sendo assim, a globalização não corresponde a algo que emana do global, mas, sim, de um processo de difusão massiva de fenômenos locais, os quais, ao se difundirem, relegam a outros elementos o status de local. Aplicando a interpretação do autor a essa divisão, pode-se afirmar que os "globalizados" são os agentes do que ele denomina localismo globalizado, ou seja, dos processos de globalização de algo local. Os excluídos, por sua vez, são as vítimas desse processo e os que sofrem, portanto, o efeito tendencioso da destruição/reestruturação. Este é o denominado globalismo localizado, que vitimiza principalmente a população pobre dos países subdesenvolvidos.

A globalização tanto divide como une; divide enquanto une - e as causas da divisão são idênticas às que promovem a uniformidade do globo. Junto com as dimensões planetárias dos negócios, das finanças, do comércio e do fluxo de informação, é colocado em movimento um processo "localizador", de fixação no espaço. Conjuntamente, os dois processos intimamente relacionados diferenciam nitidamente as condições existenciais de populações inteiras e de vários segmentos de cada população. O que para alguns parece globalização, para outros significa localização; o que para alguns é sinalização de liberdade, para muitos outros é um destino indesejado e cruel (BAUMAN, 1999, p. 8).

É neste contexto de isolamento globalizado que se constrói o neoliberalismo periférico, ao qual o Brasil, junto a tantos outros países subdesenvolvidos na América Latina e fora dela, se submete, porque é preciso "dançar conforme a música", que é "cantada" pelo bloco econômico globalmente dominante. O cenário, cada dia mais desolador, agrava-se diante da má-gestão da coisa pública, eficiente apenas na hora de arrecadar tributos, que utiliza a proposta constitucional de um Welfare State pleno para justificar o agigantamento do Estado e sua incansável burocratização.

\section{CONSIDERAÇÕES FINAIS}

A partir das premissas teóricas levantadas neste artigo, foi possível compreender que, embora o texto constitucional tenha ofertado a proposta de um welfare socialdemocrata, cuja pretensão seria dirigir os governantes a consolidar um sistema de proteção universal e integral de serviços públicos essenciais, foram encontrados inúmeros entraves práticos que impediram a realização da proposta constituinte.

Além do claro tom idealista, que beira o completo desconhecimento da realidade socioeconômica do país, um dos maiores entraves reais consistiu na imposição da agenda neoliberal, como decorrência de pressões internacionais que tomaram força em tempos globalizados. Ciente de que ceder era inevitável e de que se submeter ao isolamento econômico seria ainda mais gravoso, o Brasil foi o último dos países da América Latina a efetivar o modelo neoliberal, bastante rejeitado pela população - prova disso está no teor da própria norma constitucional, que tem poucos indícios políticos de cunho neoliberal.

Neste cenário, luta-se por atender minimamente os interesses constitucionalmente eleitos como prioritários, mas efetiva-se o pior dos modelos de Welfare State, característico como altamente oneroso para o Estado, porém injusto para com o cidadão, que é o conservador e corporativista, ou institucional-redistributivo. Assim, tem-se a consolidação de um welfare que apenas serve para justificar o agigantamento estatal, numa máquina cada vez mais burocrática e corrupta, mas tem pouca utilidade para reduzir desigualdades. 
O welfare neoliberal periférico une o pior dos dois mundos: o Estado agigantado e burocrático, que justifica seus altos custos e seu predadorismo arrecadatório com base nos deveres constitucionalmente erigidos de efetivar o bem-estar social, mas que, na prática, sofre em meio à má-gestão e à corrupção escancarada de seus gestores e pouco entrega do que promete; e o mercado globalizado, com um empresariado tão preocupado em obter cada vez maiores lucros que, inevitavelmente, tende à precarização do indivíduo trabalhador, cada dia mais exigindo de sua capacidade produtiva e menos retornando em qualidade de vida.

\section{REFERÊNCIAS}

ANDERSON, P. Balanço do neoliberalismo. In: SADER, E.; GENTILI, P. (org.). Pós-neoliberalismo: as políticas sociais e o Estado democrático. 4. ed. São Paulo: Paz e Terra, 1995.

ARAÚJO, C. R. V. História do pensamento econômico: uma abordagem introdutória. São Paulo: Atlas, 1988.

BAUMAN, Z. Globalização: as consequências humanas. Tradução Marcus Penchel. Rio de Janeiro: Zahar, 1999.

COASE, R. The nature of the firm. Economica, New Series, v. 4, n. 16, p. 386-405, nov. 1937.

FILGUEIRAS, L. A história do Plano Real: fundamentos, impactos e contradições. São Paulo: Boitempo, 2000.

FILGUEIRAS, L. O neoliberalismo no Brasil: estrutura, dinâmica e ajuste do modelo econômico. In: MASUALDO, B.; ARCEO, E. (org.). Neoliberalismo y sectores dominantes: tendencias globales y experiencias nacionales, Buenos Aires: Clacso, 2006. p. 179-206. (Colección grupos de trabajo).

FIORI, José Luís. Estado de bem-estar social: padrões e crises. Rio de Janeiro: Uerj; IMS, 1995. (Série estudos em saúde coletiva, n. 117).

KEYNES, John Maynard. A Teoria geral do emprego, do juro e da moeda. São Paulo: Nova Cultural, 1996.

HAYEK, F. A. Law, legislation and liberty: a new statement of the liberal principles of justice and political economy. Londres: Routledge, 1998. V. 1.

HUNT, E. K. História do pensamento econômico. 2. ed. Rio de Janeiro: Elsevier, 2005.

LEME, A. A. Neoliberalismo, globalização e reformas do Estado: reflexões acerca da temática. Barbaroi, Santa Cruz do Sul, n. 32, jun. 2010. Disponível em: http://pepsic.bvsalud.org/scielo. Acesso em: 1o mar. 2018.

NAPOLEONI, C. Curso de economia política. 8. ed. São Paulo: Paz e Terra, 2000.

PÉREZ GÓMEZ, A. I. A cultura escolar na sociedade neoliberal. Porto Alegre: Artmed Editora, 2001.

PETRY, A. Neoliberalismo e globalização na América Latina. Revista da Universidade do Vale do Rio dos Sinos, Unisinos, 2007. Disponível em: http://www.projeto.unisinos.br/humanismo/al/neoliberalismo.pdf. Acesso em: 29 jul. 2019.

SANTOS, B. de S. Os processos da globalização. In: SANTOS, B. S. (org.). Globalização: fatalidade ou Utopia. Porto: Afrontamento, 2001.

SMITH, Adam. A riqueza das Nações. São Paulo: Nova Cultural, 1996. 